\title{
LIBROS
}

\section{Days of Death, Days of Life: \\ Ritual in the Popular Culture of Oaxaca}

\author{
Kristin Norget \\ Columbia University Press, Nueva York, 2006
}

Kristen G. Meckel-Parker

En Days of Death, Days of Life: la conservación de cierta senRitual in the Popular Culture of sibilidad estética, parte de una Oaxaca, Kristin Norget analiza experiencia compartida de la las formas en que las clases po- vida y la muerte" (p. 168). Norpulares en Oaxaca interactúan con la muerte. Mediante tomas fotográficas en blanco y negro, narraciones de los residentes de una colonia que ella llama "San Juan", notas de campo y una extensa investigación, Norget describe de manera impresionante y permite al lector interpretar, hasta cierto punto, los rituales de la muerte en esa zona del estado sureño mexicano. La autora percibe que los rituales de la muerte son "mnemotécnicas culturales para get interpreta estos rituales y su relación entre la vida y la muerte como intercambios sociales. Las comunidades se forjan y reafirman entre los vivos, y entre los vivos y los muertos, a través de una variedad de costumbres tradicionales. El equilibrio es crucial en las conectividades que permiten a los miembros de la comunidad acoger ceremonias inclusivas que ayudan a los muertos en su viaje al cielo. Como Norget afirma, la suya es una exploración en torno al 


\section{Culturales}

papel que desempeña la religión popular en la conformación de las percepciones que la gente tiene de sí misma.

Parece que en un contexto político y económico que es -como resulta serlo para muchos mexicanos marginales-incierto e inestable, $y$ en el que la muerte, el sufrimiento y la violencia son presencias tangibles en la vida cotidiana, muchas de las personas sobre las que escribo se han apoderado del poder especial de la muerte y de las prácticas sociales ocasionadas por ésta para simbolizar para sí mismos -y unos para con otros-qué es lo más importante para ellos (p. 14).

El libro de Norget consiste en una introducción y tres secciones. Cada una de éstas contiene dos capítulos que conducen al lector por los ritos de la vida y la muerte popular en Oaxaca y lo llevan a experimentar el Día de los Muertos. La autora dedicó mucho tiempo a estudiar la colonia que ella llama "San Juan": originalmente, un asentamiento de "paracaidistas" en las afueras de la ciudad de Oaxaca compuesto por migrantes rurales. Esto vuelve su narrativa bastante creíble. Durante sus múltiples estadías y visitas, Norget se rela- cionó de cerca con individuos de la comunidad y así pudo asistir a (y observar) numerosos rituales relacionados con la muerte.

Desde una perspectiva "occidental", la muerte es una experiencia bastante íntima, así que en otro contexto, de no formar parte de la familia, resultaría bastante difícil que a uno se le incluyera en el proceso de luto. En Oaxaca, sin embargo, entre más gente asiste a los rituales de la muerte, más fácil es para el difunto continuar su camino a la otra vida. Seguramente que Norget tuvo que superar sus propias emociones respecto a la dimensión íntima de la muerte para no sentirse incómoda cuando participó en rituales mortuorios de individuos que no conocía.

Para los oaxaqueños que viven en barrios humildes, la muerte no es el fin de la vida, sino una transformación de la persona en la que el alma se separa del cuerpo. El luto es un evento comunal que no permite que ningún residente permanezca solo durante su penar. Las cuestiones personales y las riñas son abandonadas a la entrada de la casa del difunto, donde los indi- 


\section{Culturales}

viduos de la colonia se reúnen y lo recuerdan como si aún se encontrara entre ellos.

Los rituales de la muerte en Oaxaca son menos íntimos que en Estados Unidos o Canadá. Aunque los residentes de la colonia creen que complace a Dios ver un velorio muy concurrido, esto no significa que los rituales de la muerte se anuncien o difundan para que aumente la asistencia a ellos. La muerte en Oaxaca no es espectacular. Con esta advertencia, es importante entender cómo la popularización del Día de los Muertos ha modificado al festejo mismo. El turismo desempeña un gran papel ahora en cuanto a cómo se ha comercializado ese día.

Los altares que antiguamente se montaban en las casas para que los parientes difuntos los visitaran el 2 de noviembre, ahora se encuentran en lugares públicos durante más largos periodos. El capitalismo ha influido para que algunos, lejos de conmemorar a sus muertos dentro de la comunidad, los comercialicen para los turistas. Son los humildes quienes continúan montando altares el Día de los Muertos en sus hogares, mien- tras que los ricos piensan que los muertos se han marchado para siempre y no ven razón alguna para construirles un altar.

Uno de los temas principales que Norget discute a lo largo de su libro es la distinción entre ricos y pobres y lo que significa la palabra "clase" para los residentes de la colonia. Mucha de la investigación que los antropólogos han realizado en Oaxaca se centra en poblaciones indígenas, y el que una antropóloga se enfoque ahora en las clases populares, que representan gran parte de la población urbana, es muy afortunado.

La conciencia de clase está continuamente presente en una ciudad en donde los ricos viven en el centro y los pobres en la periferia. Pero en Oaxaca la pobreza se equipara con la virtud y el arraigamiento ontológico, mientras que a la riqueza se le asocia con la avaricia, el egoísmo y la superficialidad (p. 68). Según uno de los residentes, "nosotros, los pobres, tenemos más fe porque tenemos más necesidades" (p. 69). No es atípico que un pobre asista al velorio de un rico, mientras que es infrecuente que a un rico se le vea en el velorio de una persona pobre. 


\section{Culturales}

Parece como si los ricos hubieran asumido una ideología de carácter más "occidental" en relación con la muerte, mientras que los pobres siguen practicando los métodos tradicionales de encargarse de sus parientes difuntos. Quizá esto se derive del hecho de que la muerte sea más común entre los pobres.

Las personas marginales no están protegidas de la muerte de la misma manera en que lo están los ricos; ellas mueren más frecuentemente, más violentamente y más a menudo de enfermedades evitables, de accidentes y de partos en sus hogares (p. 226).

O tal vez, como sugiere Norget, todo tenga que ver con lo que ella teme que se trate de la pérdida de una práctica cultural. Como antropólogos, sin embargo, no deberíamos imponer nuestros propios valores sobre aquellos a quienes estudiamos, y la autora admite que sus deseos de que se mantengan vivas las prácticas culturales pueden no coincidir con los de los individuos en Oaxaca.

Al discutir la evolución de la religión popular en Oaxaca a lo largo de la historia, Norget nota que parece como si los indígenas frecuente y exitosamente han adaptado sus propios conceptos religiosos, dentro de un proceso de síntesis religiosa creativa capaz de eliminar muchas de las señales visibles de una "idolatría" ancestral: las evidencias físicas se perdieron, pero permaneció lo metafísico (p. 95).

Norget dedica buena parte de su libro a subrayar la centralidad de la religión en la cultura popular. Ella aborda varias prácticas religiosas que conforman "la realidad cotidiana sensata de los grupos sociales humildes" (p. 268). Las relaciones de compadrazgo, que ratifican sentimientos de respeto y confianza entre los miembros de la comunidad, así como la muy necesitada reciprocidad financiera, ejercen un papel preponderante en la colonia. Los santos también son importantes en Oaxaca en cuanto a que "los lazos entre los creyentes y los santos a menudo se asemejan a los vínculos entre compadres (ritual de parentesco)" (p. 82).

Las imágenes o estructuras que representan todo lo sagrado mantienen el poder de lo divino y se convierten en una realidad tangible que está presente todos los días en Oaxaca. Las obras 


\section{Culturales}

comunitarias apoyadas por la Iglesia, como lo que una vez fue la cofradía de la colectividad y que se ha convertido en el sistema individual de cargo, permiten que la colonia continúe.

Dentro de un marco religioso popular, las acciones individuales no son simplemente cuestión de responsabilidad personal sino que tienen un impacto en la comunidad en su totalidad (p. 85).

Existe un delicado equilibrio entre el individuo y la colonia mediado por la reciprocidad: como la guelaguetza o intercambio exacto de regalos, la construcción de lazos comunales y la dualidad de la vida cotidiana.

Mientras leía Days of Death, Days of Life, me sentí conectada con la autora de múltiples maneras. No sólo soy una "gringa" que ha realizado trabajo de campo en una colonia en las afueras de la ciudad de Oaxaca, sino que también tuve que resignarme a vivir con mis propios cuestionamientos como antropóloga y sentir cómo éstos afectan la forma en que veo e interpreto las cosas. Norget lidia con la dificultad de cómo aplicar un marco teórico en su trabajo sobre la muerte en Oaxaca. Antes de ir al campo, yo también me sentí frustrada y restringida por la intimidante tarea de comprender cómo la teoría ejercería un papel preponderante en el análisis de mi trabajo.

Es fácil asistir a una clase y entender la importancia de la teoría. Esto nos permite comparary contrastar nuestras experiencias con las de otros antropólogos. También nos permite guiar nuestro análisis a través de diferentes escuelas de pensamiento. La teoría contempla las dimensiones espaciales, temporales e intelectuales de la antropología. Pero el acercamiento filosófico no es siempre el más claro. Tomar eventos de la vida real y tratar de colocarlos en un marco ya estructurado no es fácil. Yo siento empatía por la carencia de teoría de Norget, y sin embargo entiendo que en un mundo académico reciba retroalimentación negativa de sus colegas por no incluir la teoría en su análisis.

Uno de los puntos más sólidosy que aprecio de la obra de Norget es el que utilice secciones enteras de sus notas de campo como medio para transportar al lector a un evento que experimentó durante 


\section{Culturales}

su temporada en el campo. Más que analizar rituales específicos de la muerte en retrospectiva al momento en que Norget bosquejaba su libro, sus notas de campo capturan sus primeras reacciones e interpretaciones directas de los eventos durante los periodos en que vivió en Oaxaca.

Tras experimentar en lo personal la agonía que implica tomar notas de campo, encontré bastante alentador ver cómo éstas se pueden utilizar como pasajes en la etnografía. Mientras conducía mi propia investigación en Oaxaca y Buenos Aires, luché noche a noche para recordar detalles de lo que había ocurrido en el campo durante el día y anotar todos esos detalles en mi cuaderno.

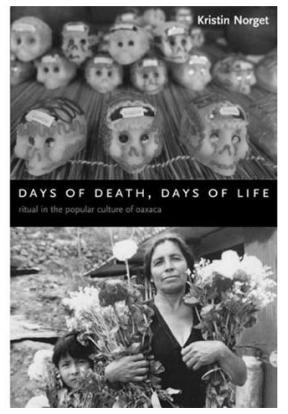

Days of Death, Days of Life:

Ritual in the Popular Culture of Oaxaca

Kristin Norget

Columbia University Press, Nueva York, 2006
Casi siempre me retrasaba en cuanto a mis notas de campo, lo que convertía a mis anotaciones sobre los eventos de varios días en una tarea mucho más compleja. Aunque quizá Norget no fue tan perfecta en torno a cómo registró sus notas de campo, lo que importa es que lo registró todo con tanta determinación que pudo consultar sus anotaciones para explicar a través de su propia mirada lo que significaba un "cabo de año" o un "novenario" en la colonia San Juan.

Definitivamente, añadiré este texto a la revisión bibliográfica que estoy compendiando antes de escribir mi tesis sobre Oaxaca. Estoy segura de que citaré, posiblemente en múltiples ocasiones, las nociones de Norget sobre las colonias populares oaxaqueñas. Varios antropólogos reconocidos por su trabajo de campo en Oaxaca, como Jeffery Cohen y Ramona Pérez, han revisado su libro y lo han alabado.

Para mí ésta resultó ser una lectura muy agradable, y si alguna vez se me presenta la oportunidad de conocer en persona a Kristin Norget, la aprovecharé sin dudarlo un segundo. 